\title{
The impact of work motives and motivation as a means to achieve job satisfaction and performance in the organization
}

\author{
Mohammad Klaib Ibraheem Alsoub \\ Research Scholar, Department of political science, Aligarh Muslim University
}

\section{INTRODUCTION:}

In his progress within his work, and in order to continue giving and develop his level, and raise the efficiency of his production in quantity and quality, and this is through training and gaining experience, the individual needs incentives, which are financial gain Or moral, in order to motivate the employee and push him to increase production.

Motives and incentives are among the basic influences that play an important and vital role in the behavior of Individuals, through which they can create a desire to achieve job satisfaction, which can Saying with him that the ability of organizations to achieve their goals depends on the management's success in providing destiny Sufficient motivation of individuals with the development of an effective system of incentives, in turn, directed to raise the motives that in turn push the workers to production and achieve job satisfaction for that work in the organization, which leads to raising morale and increasing performance rates.

In addition, the incentive system differs from one organization to another, according to the nature and role of each Foundation within the community

But there is no difference from the fact that these incentives have two main parts, which are material incentives and Other, moral, and there are several ways that each organization takes separately, to employ these incentives to reach the maximum degree of benefit for the employee and the organization.

The concept of motives: the behavior of the individual depends on the type of motives that affect him, given that the motive and the basis of the behavior is the motive, and it has different types that affect the behavior of the individual, some of which are material and some are moral.( Boumahama Jyal Yale,2006)

Definition of Motivation: An individual's desire to demonstrate the effort necessary to achieve organizational goals, so that this effort enables the satisfaction of the individual's needs, just as the unsatisfied need leads to a specific behavior of the individual. Depending on the strength of the motive, this behavior is determined. The search for food comes from a natural physiological reality, which is hunger, and once this need is satisfied, this behavior ends.

A set of driving forces within the human personality, causing a kind of imbalance and tension.

This unsaturated need pushes the individual towards achieving certain goals, by practicing some types of behaviors, to express the need that drives him to perform behavior, in order to achieve a specific goal.( Adel Hussein,1998)

Motives of human behavior: the individual seeks to satisfy his missing need, which results in a kind of tension that pushes him to do a certain behavior that leads to the motive, which is an internal tension that pushes the individual to achieve a specific goal, the study of motives helps to predict human behavior, if we know the motives of an individual, we can predict his behavior in certain circumstances, and we can use our knowledge of the motives of the individual, in controlling and compelling his behavior to certain destinations, so we create some special situations that will provoke in him certain motives, motivate him to do the actions we want him to perform, and prevent him doing some other work that we don't want him to do.

Psychological work motives: The individual feels reassured about his health, his work and the future of his children, and he is surrounded by various social insurances against work accidents, occupational diseases, and unemployment. mental health conditions, if the equilibrium the psychological basis of the individual has a secure basis, and the security of the group is based on social reform. Some researches have indicated the relationship between material and moral incentives, the health of the psychological factor, and the increase in its production.

Social work motives: to be appreciated and respected by others, and to have a position and a social value, and his feeling of social importance, and that his presence and efforts have a value that affects others, because social appreciation enhances a sense of security and increases the desire for teamwork.

Work and the need for self-realization: it means that the individual directs all his energies and potentials to exploit them within his field of work, to reach his ambitions and goals, and these needs are what motivate the individual to express himself and prove his personality, and to perform positive actions of beneficial value to others by doing the work entrusted to him.( Vallerand, J. Et,1993) 


\section{International Advanced Research Journal in Science, Engineering and Technology \\ Impact Factor 7.105 Vol. 9, Issue 1, January 2022 \\ DOI: 10.17148/IARJSET.2022.9111}

Achievement motives: The individual feels a desire to assert himself in his work, through the innovations, developments and improvements that he presents at work, and his sense of the effort and work he is doing in line with the desired goals, which the state seeks in general and institution in particular to achieve.

Motivations of the individual to good performance and high production: One of the factors of the success of the organization is the application of a special system of incentives, using all possible and available means to urge the individual employee to make effort and good work, and there are several visions that define incentives as an external stimulus that works on creating and motivating the individual's internal motivation positively towards obtaining the incentive, which leads to the individual's satiation for a specific behavior consistent with the performance requested by the employer. From this perspective, a distinction can be made.

Between the stimulus and the motive, the first is external, while the second is internal, stems from within the human being. The stimulus can stir and awaken the motive for good performance and higher production. Hence, motivation is viewed on the basis that it is a phased and multiple process that passes through several steps, before reaching it the process of gratification and satisfaction.( Abdul Ghaffar Hanafi,1996)

- The emergence of internal needs and desires, which are represented by tension and imbalance in the individual.

Research and choose from among several alternatives to satisfy these needs.

The behavior and goal followed to satisfy the individual's need.

Connecting needs and calendar.

The stage of punishment, whether it is correct or a punishment, depends on the quality of the performance appraisal used to satisfy individual need.( Eric COBUT,2009)

Reasons for paying attention to job satisfaction: The job satisfaction of employees is one of the most important indicators of health and wellness for the organization, and its effectiveness in the organization in which employees are not satisfied will inevitably be of little success.

And profitability and productivity, compared to those in which employees feel satisfied. An employee who is satisfied with his work is more willing to continue his job and achieve the goals of the organization. He is also more active and enthusiastic at work. and the environment around it, and for these reasons:

- The high level of job satisfaction leads to a high level of ambition among the employees of the organization.

- The workers who are more satisfied with their work are less prone to work accidents.

- There is a strong relationship between job satisfaction and production, ---The higher the degree of satisfaction, the higher the production.

- The high level of job satisfaction leads to a high level of ambition among employees.

Organizational factors of job satisfaction: they include the system, texts, procedures, salaries and material incentives and morale, the type of leadership and how to make decisions, control and supervision, human relations at work among colleagues, the relationship of each working individual with his work environment, conditions and type work, and in previous studies confirmed that if money income is appropriate for the working individual, it achieves a high degree of satisfaction, and provides him with opportunities for promotion at work, in addition to the prevailing supervision in his work environment. And the degree of control imposed on the various activities practiced by the working individual.

From the foregoing, there are two important factors for job satisfaction. The first is directly related to work, and the second factor is related to other circumstances and aspects of work.

A- Factors directly related to work: There are important factors for job satisfaction, and they are three factors directly related to work, including:

- Efficiency of direct supervision: This work is the task of the supervisor, because it is an important link and point of contact between the organization and the working individuals, and it has a significant impact on the activities that individuals do.

- Satisfaction with the work itself, here most of the individuals feel satisfied with the work, if the latter is a type they like and love, and this satisfaction is a reality for them to master the work, and increase production.

- Integration with co-workers: If the worker feels that he has a permanent opportunity to interact with other co-workers, then the person is a social being by nature, in this case the work for the individual has the effect of satisfying him.

b- Factors related to other circumstances: These factors are related to other circumstances and aspects of work, and they are three factors that we mention,

To provide goals in the organization: working individuals want to be members of an organization a well-thought-out and acceptable goal, from their point of view, and there is an acknowledgment by the workers that this organization is highly effective, enabling them to achieve the goal.

Equitable Remuneration: Employees expect to receive a fair remuneration, compared to each other within the organization on the one hand, and on the other hand, whether compared to what they receive employees from other similar organizations.

Physical and mental health status: The organization must be very careful about these cases, because there is a link between physical health and mental health, from their impact on the working individual, his performance and his morale. 


\section{International Advanced Research Journal in Science, Engineering and Technology \\ Impact Factor $7.105 \div$ Vol. 9, Issue 1, January 2022 \\ DOI: 10.17148/IARJSET.2022.9111}

The nature and philosophy of incentives: the motivation is internal, felt by the individual and shapes his behavior, and the incentive is an external factor that addresses the motivation and directs his behavior. (aljazaar,2006)

Characteristics of a good incentive system: to achieve the goal of developing an effective and good incentive system, a number of conditions must be observed.

- Compatibility of the incentive with the existing motivation of the individual, that is, if the incentives given to the employees are consistent with their desires and needs, this leads to the effectiveness of the incentive system.

- Incentives work to link the individual with the organization in which he works and his interaction with it.

- These incentives keep pace with the economic and social changes that the state is going through that may affect the behavior of workers.

- Link these incentives to the physical and mental effort made by the worker, to achieve performance and productivity.

- That the effective incentive system focus on satisfying the individual's motives, because they are the ones that control his behavior and actions.

The effect of incentives on behavior and performance: Incentives are considered as equivalent to performance and behavior, for example, we find that an employee who needs money, the feeling pushes him to search for work, there is a motive followed by the worker to provide his best money for work, which affects and is reflected in a way positive job behavior.

One of the advantages of incentives is that it reduces the rate of work turnover, and attracts qualified personnel, considering that it affects the motivation of the individual, so that individuals turn permanently to the path that achieves

Reward, and therefore the incentive is considered a motivator for performance, and incentives help to reinforce patterns of individual behavior, as they deal with unsatisfied needs, and work to direct the individual

To choose from among the alternative patterns of behavior, as it works and is keen on the direct link between motivation and performance and not to confuse the motives and morale of the employees, the employees may be cheerful and happy, But there is no reason for them to increase their production, because the lack of effective planning of the workforce inevitably leads to the subjectivity of the incentive, in addition to the misuse of the authority to grant incentive by some officials who focus on the negative side of the incentive, at the level of the organization the incentive system is affected by three factors, the first of which is qualitative The administrative apparatus, its capabilities, and its organization, and the second is the supervisory style of the employees that the president follows in his leadership of his subordinates and their direction.

fear of punishment, The administrative concept for this is that the leadership is democratic. Therefore, the change related to the style in the official's relationship with employees is achieved through the following three aspects:

- The official's interest in work, which makes him a good role model for employees.

- $\quad$ Respect the person responsible for his subordinates.

- $\quad$ Distribution of work according to employee capabilities.

Factors affecting incentive systems: It is that the organization follows the application of the wrong incentive system, for example, equality between workers who work and those who do not work, and therefore incentives lose their value, in stimulating workers to make an effort, and to avoid these influences, the organization can activate and apply these factors.( MAUGERI,2008)

- Direct Communication: No chief can achieve interaction between him and his subordinates without providing them with an appropriate system of direct communications without any restrictions so that they can direct their efforts and clarify the various actions they are required to carry out. During the efforts of his subordinates and correct their mistakes, and at the same time, through the information available to him, he decides the rewards or penalties that should be granted to the subordinates.

- Working conditions: The boss has an important and significant role in creating the best physical conditions for subordinates, such as improving lighting, temperature, ventilation, hygiene, controlling public order and applying

- The laws inside the workplace, the provision of necessary and basic facilities for the worker, such as toilets, the provision of modern work tools and devices, and taking all necessary precautions to protect workers from hazards and work injuries and other aspects and conditions that management should work on improving and providing, as this helps to increase productivity and raise morale among workers, and attachment to work.

- Organizational aspects, including wage policies, bonuses, promotions, and positions functional, work policies and procedures, which mean the organizational field in which the employee works, the organizational structure of the organization, and the diversity of the organization's incentives to work within the framework of allowing the space to satisfy individual needs, which includes what the salary provides in exchange for the necessary needs satisfying the social and psychological needs of the working individual within the framework of the applicable organizational structure, and the management style that is reflected in work policies and procedures, 


\section{International Advanced Research Journal in Science, Engineering and Technology \\ Impact Factor $7.105 \div$ Vol. 9, Issue 1, January 2022 \\ DOI: $10.17148 /$ IARJSET.2022.9111}

which leads to qualification, skill and training, which diversifies activity, effectiveness and yield. (Mohammed,2000)

The relationship between satisfaction and job performance: There is a difference in viewpoints regarding the relationship between satisfaction and performance, there is one group that says that satisfaction affects performance, and the other group says that performance affects satisfaction.

Satisfaction and performance: There is a direct relationship between workers, that is, providing satisfaction with workers will lead to high performance. The first is independent, which is satisfaction, and the second is dependent, which is performance. the higher the levels of satisfaction, the higher the performance rates.

Performance and Satisfaction: Satisfaction is only a variable dependent on an independent variable, which is performance, on the basis of which the good performance of the employee and the subsequent rewards, leads to an increase in performance. his ability to satisfy his needs and thus increase his degree of satisfaction.

Organization climate: as a mediating factor between satisfaction and performance, this view focuses on the organization's climate, as it is the mediating factor between satisfaction and performance, as it is the mirror that reflects the impression that the employees of the organization, and as long as these are the primary means of doing business and achieving goals, the more positive the image of the organization is, the more it raises morale, and improve their performance. (Badr,2007)

\section{CONCLUSION :}

Implementing a special system of incentives, which is considered one of the most important factors for success in the organization, using all possible means to motivate employees to do good work, and incentives are known as an external influence it works to move the internal motivation of the individual positively, and the incentive is one of the elements of organized and institutional work, without which no institution can achieve its full goals. It is one of the ways that helps the organization achieve its goals, by providing the material and financial capabilities, as well as the experience of the organization's employees, each in his field of specialization.

Incentives cannot achieve their goals in the organization, unless there is a specific system to manage them in a good and optimal manner, with the availability of credibility and justice in the application of the incentive system within the organization, to be granted to their owners without distinction, and that the incentive is based on the work, because this leads to achieve the organization's role and objectives.

\section{REFERENCE:}

Abdel Wahab Ali Mohamed, "People Management and Human Relations", Ain Shams Library, Cairo, Egypt, 2000. Mubarak bin Ali Al-Jazzar, "Job Satisfaction among Employees,” Naif Library, Riyadh, Saudi Arabia, 2006.

Hamed Badr, "Job Satisfaction for Faculty Members at the Faculty of Commerce and Economics", Journal of Science Social, No. 11, Kuwait, 2007.

Bouhamama, Jila Lee, Abd al-Rahim Anu Riyad and al-Shahoumi Abdallah, "Psychology of Learning and Education", Al-Ahlia - for Publishing and Distribution, Kuwait, 2006.

Eric COBUT, Géraldine BOMAL, Motiver, être motivé et réussir ensemble, Edition Edipro, 2009.

Salvatore MAUGERI «Les théories de la motivation au travail - histoire et actualité - »’2008 Orléans Cedex France' 